\title{
Understanding the Effects of Nutrient Concentration on Mercury Cycling within Fluvial Periphyton
}

\author{
SPENCER J WASHBURN ${ }^{1}$, MELISSA CREGGER ${ }^{1}$, \\ ALYSSA CARRELL ${ }^{1}$, GRACE SCHWARTZ ${ }^{1,2}$, DWAYNE \\ ELIAS $^{1}$ AND SCOTT C BROOKS ${ }^{1}$
}

${ }^{1}$ Oak Ridge National Laboratory

${ }^{2}$ Wofford College

Presenting Author: washburnsj@ornl.gov

Periphyton biofilms play an important role in the biogeochemical cycling of mercury $(\mathrm{Hg})$ within watersheds, but relatively little is known about the impact of nutrient concentrations on the methylation and demethylation potentials of the complex consortia of microbiota within these biofilms. Nutrient conditions impact periphyton productivity and composition, but nutrient driven changes to the Hg-methylating microbial community within fluvial periphyton are poorly characterized. To address this knowledge gap, we are conducting experiments to better quantify the effects of nutrient concentrations on the net $\mathrm{Hg}$ methylation and methylmercury (MeHg) demethylation potentials of periphyton, periphyton microbial community structure, and the production of specific low molecular weight thiol compounds by organisms within biofilms. A translocation experiment utilizing a natural gradient of nutrient concentrations between locations within the $\mathrm{Hg}$ impacted East Fork Poplar Creek (EFPC, located in Oak Ridge, Tennessee, USA) is being conducted to assess what changes in periphyton community and $\mathrm{Hg}$ methylation potential are associated both with biofilms colonized under relatively low and high nutrient concentrations, as well as the impacts of altering the nutrient regime to which an established periphyton community is exposed via physical translocation between locations. To control for seasonal variation in periphyton community composition within EFPC, this experiment is being replicated across multiple seasons. Preliminary results from winter season $\mathrm{Hg}$ methylation time-course analyses indicate that there is a significantly different $(\mathrm{p}<0.05)$ production of $\mathrm{MeHg}$ between the two sites when controlling for incubation time and nutrient level, with a negative relationship between nutrient loadings and methylation. No significant differences in $\mathrm{MeHg}$ demethylation are observed between the two sites, but a full analysis of the rates of $\mathrm{Hg}$ methylation and $\mathrm{MeHg}$ demethylation will be conducted after application of a transient availability model for $\mathrm{Hg}$ methylation and $\mathrm{MeHg}$ demethylation tracers previously developed for this system. ${ }^{1}$ This work aims to improve our understanding of how future anthropogenic activity, including land use change and runoff management practices, will impact the production of $\mathrm{MeHg}$ within stream ecosystems.

REFERENCES

${ }^{1}$ Olsen, T. A., Muller, K. A., Painter, S. L., \& Brooks, S. C. (2018). Kinetics of Methylmercury Production Revisited. Environmental Science and Technology, 52(4), 2063-2070 